\section{Early Treatment Diseases}

\section{Michael R McGuire}

161 N Civic Dr. \#240 Walnut Creek, CA 94596, USA

“Corresponding author: Michael R McGuire, 161 N Civic Dr. \#240 Walnut Creek, CA 94596, USA, Tel: +5104177382; E-mail: michaelrichardmcguire@gmail.com

Received date: October 29, 2018; Accepted date: November 01, 2018; Published date: November 07, 2018

Copyright: (c) 2018 McGuire MR. This is an open-access article distributed under the terms of the Creative Commons Attribution License, which permits unrestricted use, distribution, and reproduction in any medium, provided the original author and source are credited.

Citation: McGuire MR (2018) Early Treatment Diseases. J Health Educ Res Dev 6: 282. DOI: 10.4172/2380-5439.1000282

\section{Early Treatment Diseases}

Today the practice of medicine mainly involves [1] treating medical conditions after symptoms of the medical condition become obvious (e.g., setting a fracture or treating pneumonia), or [2] preventing a disease for a population of patients using a preventative that has few side effects (e.g., vaccinations).

In the future, medicine will be more and more [1] predicting that a disease will occur for an individual and [2] treating the disease before it occurs, either stopping the disease or lessening the effects of the disease. I call such diseases early treatment diseases [3].

An example of an early treatment disease is colon cancer. During a colonoscopy, polyps, which could later turn into cancers, could be removed [4]

Another current example of an early treatment disease is BRCA2 or BRCA2 related breast cancer.

Mutations in the BRCA1 or BRCA2 genes in a woman could result in a greater than $80 \%$ chance of a woman having breast or ovarian cancer in her lifetime [2]. Treatment to decrease the chances of these cancers occurring is a double mastectomy and salpingo-oophorectomy [1].

Early treatment is most important for a disease where the disease is devastating at the time that symptoms are obvious. Such a disease is Alzheimer's disease, so hopefully Alzheimer's will be both detectable and treatable in the future before symptoms of the disease occur.

This could theoretically be done by halting disease pathways in cells that result in Alzheimer's.

A disease pathway is a set of genetic and environmental factors that cause a cell to function abnormally, leading to disease (https:// rgd.mcw.edu/rgdweb/ontology/view.html?acc_id=PW:0000013).

In the future, prediction of a disease will be enhanced by greater use of the genome in medicine and by identifying disease pathways occurring within cells that lead to a disease.

Treatment before a disease occurs will be enhanced by treatments that disrupt these disease pathways halting or lessening a future onset of the disease.

Early treatment will significantly change the way medicine is practiced and require medical education to change. The following identifies some ways that medical practice will change:
- Prediction, loosely "diagnosis" and treatment of a disease will occur for a patient before there are any obvious symptoms of the disease.

- The patient may not wish to have knowledge that he/she will likely get the disease and thus may not agree to prediction or treatment.

- Prediction of the disease may only be possible during a given time frame before the disease occurs.

- Treatment may also only be possible during a given time frame. Certainly, treatment should occur before, possibly long before, there are obvious symptoms.

- Prediction or treatment of the disease has the potential of causing harm, so a false positive prediction could cause harm to the patient without any benefit.

- Since the process of prediction of a disease could cause harm, then only selected patients (e.g., with a particular genetic makeup) may be candidates for early treatment of a given disease.

- Insurance companies may be reluctant to pay for early treatments as the disease has not yet obviously occurred.

Principle differences in medical care are then [1] that a patient must be convinced to come in for care when the patient is not sick, and [2] the patient must be scheduled for diagnosis and treatment within given time frames before the onset of symptoms of disease.

Further, the process could cause harm or discomfort to the patient, although it has a chance of providing a much greater long-term benefit for the patient.

\section{References}

1. Domchek SM, Friebel TM, Singer CF (2010) Association of RiskReducing Surgery in BRCA1 or BRCA2 Mutation Carriers with Cancer Risk and Mortality. JAMA 304: 967-975.

2. King MC, Marks JH, Mandell JB (2003) Breast and Ovarian Cancer Risks Due to Inherited Mutations in BRCA1 and BRCA2. Science 302: 643-646.

3. McGuire MR (2018) The Future of Medicine 2030. McGuire Publishing, Walnut Creek, CA, USA.

4. Winawer SJ, Zauber AG, Ho MN, O'Brien MJ, Gottlieb LS, et al. (1993) Prevention of Colorectal Cancer by Colonoscopic Polypectomy. The New England Journal of Medicine 329: 1977-1981. 